\title{
Interculturalism, education and society: Education policies for immigrant students in I taly
}

\author{
MARI AGRAZI A SANTAGATI ${ }^{1}$ \\ Università Cattolica del Sacro Cuore, Milan, I taly \\ mariagrazia.santagati@unicatt.it
}

\begin{abstract}
The article seeks to illustrate Italian educational policies for students with an immigrant background within the context of the EU intercultural framework. Italy can be considered the EU country where interculturalism is more widely recognized in terms of pedagogical theory and school legislation. However, the Italian approach is characterized by a weak and contradictory relationship between policy, teaching strategies and educational experiences. To support this argument, I will refer to a review of Italian sociological studies, which demonstrate the strengths and weaknesses of the interculturalism as applied to the Italian education system. The conflict between theory and practices is illustrated by empirical findings that suggest immigrant students are still not granted equality of opportunity, linguistic and cultural diversities are almost absent from most school curricula, and a positive dialogue between culturally different subjects is still more of an aspiration than a fact. More research is needed in order to monitor and evaluate if intercultural practice is indeed a true expression of the ideas to which it aspires.
\end{abstract}

Keywords: Education, Interculturalism, Italy, Students with an Immigrant Background

\section{Introduction}

After a long period as a country of emigration, Italy has gradually developed into a country of immigration, reaching 5.8 million immigrants on 1 January 2015, according to the ISMU Foundation estimates ${ }^{2}$. Nowadays immigration is characterized by a stable presence, prevalently made up of families with children, long-standing residents, EU citizens (Romanians) as well as Albanians, and a large group of children without Italian citizenship $(814,187 \text { in } 2014 / 15)^{3}$. This is the consequence of a recent migratory phenomenon, which rapidly led Italy to reach immigration levels similar to those of countries with a much older history of immigration, yet without any significant experience in immigration governance. From the 1980s to 1998, inclusion policies have been characterized by instability and fragmentation and are mainly aimed at managing recent arrivals and emergencies. In the educational field, a study carried out on behalf of the European Commission suggested that Italy - much like other Southern European countries - has adopted a

\footnotetext{
${ }^{1}$ Mariagrazia Santagati, Università Cattolica del Sacro Cuore, Milano.

${ }^{2}$ The Foundation for Initiatives and Studies on Multi-ethnicity (ISMU) was created in 1991 by Cariplo Foundation. Cf. www.ismu.org.

${ }^{3}$ Cf. M. Santagati, 'Education' in V. Cesareo (ed.), The Twenty-first Italian Report on Migration 2015, Milan:

McGraw Hill, 2016, pp. 29-39.
} 
non-systematic model of integration of immigrant children, in the sense that it was characterized by the lack of national-level policies, random variations in support provided, and fragmented measures ${ }^{4}$.

Only at the beginning of the new millennium has the focus gradually turned to the need to ensure the integration of immigrants in the country's economic and social fabric ${ }^{5}$. Italy's first effort in developing social policies geared specifically to immigrants is the Turco-Napolitano Law of 1998, which aimed to ensure certain fundamental rights are granted to all residents (with or without a residency permit), including free education to all minors.

Simultaneously, since the 1990s Italy chose to adopt an intercultural model of school integration for non-Italian students. Interculturalism has been the only approach for the management of cultural diversity in the educational system and Italy can be considered the EU country where intercultural pedagogy has received the most recognition both in terms of practices and in terms of school legislation ${ }^{6}$. Interculturalism was introduced as a bridge between the educational needs of immigrants and the internationalization agenda of the EU regarding cooperation on education ${ }^{7}$.

To analyze the implementation of the Italian intercultural model, I will refer to the concept of interculturalism as defined by Giménez ${ }^{8}$. He identifies three main principles of interculturalism: the right to equality independently from culture, religion, language, ethnicity; the right to recognition and acceptance of difference; an emphasis on positive interaction between persons belonging to different cultures. In an intercultural perspective, the school system has the role of ensuring new generations are granted equal opportunities in terms of: access to different educational levels; academic success and equal treatment from teachers, independently from cultural differences. Secondly, cultural differentiation should not be constrained by standardizing the learning process. On the contrary, linguistic, cultural and religious differences are resources which ought to be recognized and accepted in order to sustain individual talents. Thirdly, as UNESCO pointed out in $2006,{ }^{9}$ interculturalism stresses the dynamic nature of cultures in order to create what could be defined a 'third space' within which natives and immigrants develop a new shared culture, through dialogue and mutual respect. In this sense, education represents the ideal place to encourage and practice of intercultural dialogue. In 2008, the Council of Europe added that dialogue should always be pursued, even with those who do not - or do not fully - share democratic values. ${ }^{10}$ In this case

\footnotetext{
4See European Commission, Study on educational support for newly arrived migrant children, Luxembourg: Publications Office of the European Union, 2013.

${ }^{5}$ E. Codini, N. Pasini, 'Managing immigration in Italy: statistical frame work and integration' in V. Cesareo (ed.), Migration: a picture from Italy, Milan: ISMU, 2013, pp. 29-38.

${ }^{6}$ A.J . Liddicoat, A. Diaz, 'Engaging with diversity: The construction of policy for intercultural education in Italy', Intercultural Education, 19, 2008, pp. 137-150.

${ }^{7}$ C. Hadjisoteriou, D. Faas, P. Angelides, 'The Europeanisation of intercultural education? Responses from EU policymakers', Educational Review, 67, 2, 2015, pp. 218-235.

${ }^{8}$ C. Giménez, 'Pluralismo, multiculturalismo e interculturalidad' in L. Díe (ed.), Aprendiendo a ser iguales. Manual de Educación Intercultural, Valencia: CeiMigra, 2012, pp. 49-65.

9 UNESCO, Guidelines on Intercultural Education, Paris: UNESCO, 2006.

10 The values upheld by the Council of Europe are considered to be a condition for intercultural dialogue, especially regarding the right to freedom of expression and other fundamental rights. Human-rights abuses, such as forced marriages, "honour crimes" or genital mutilations can never be justified whatever the cultural context. Equally, the rules of a - real or imagined - "dominant culture" cannot be used to justify discrimination, hate
} 
dialogue may be the starting point of a longer process of interaction, at the end of which an agreement on the significance and practical implementation of the values of human rights, democracy and the rule of law may be reached.

Drawing from this first definition of interculturalism given by Giménez (right to equality, right to be different, positive interaction between culturally different subjects), the present paper seeks to reconstruct Italy's educational policies for young immigrants, with the aim of clarifying how the intercultural model and intercultural practices has been implemented in this country. Italy is an interesting context in which to observe the contradictory relationship between the theory and practice of interculturalism. The argument put forth in this paper is that in Italy the intercultural model has represented more of an aspiration than a fact. To support this thesis, I will refer to a set of sociological studies (approximately 20) on interculturalism identified in a recent review of Italian studies ${ }^{11}$, which have focussed on the institutional level of school integration (more generally) and teachers' practices and strategies (more specifically) and which have been carried out either by myself or by other scholars ${ }^{12}$. Drawing on primary and secondary data deriving from these studies and applying Giménez's principles to the Italian case, I will show that: a) immigrant students, compared to natives, show persistent disadvantages in the educational system (no equality); b) linguistic and cultural diversities struggle to find recognition in the school system (right to difference is at risk); and c) a constructive dialogue between culturally different subjects still remains more of an aim, rather than an actual result, to pursue via an "intercultural revision" of the curricula and the development of a positive school environment.

The paper is structured in two parts. The first part illustrates the development of European intercultural policies for the reception and inclusion of pupils with an immigrant background in the education system. Such a premise is necessary in order to understand the Italian case and the governance choices undertaken by educational institutions in Italy, to which the second part of the paper is dedicated. Here I turn to analysing how Italy has sought to ensure equal opportunities for all pupils, by paying attention to cultural differences and fostering opportunities for intercultural dialogue.

\section{The EU implementation of the intercultural approach}

Interculturalism has been strongly promoted by the EU with the proclamation of the European Year of Intercultural Dialogue in 2008 and with the adoption of the Green Paper Migration and mobility: challenges and opportunities for EU education systems. With these actions the European Union has sought to open a debate on what strategies and policies are to be promoted across Member States in order to deal with the socio-educational issues raised by migratory phenomena. Furthermore, the European Parliament, with the adoption of the resolution of 2 April 2008 on

speech or any form of discrimination on religious, racial, or ethnic grounds. See Council of Europe, White Paper on Intercultural Dialogue, Strasbourg: www.coe.int/ dialogue, 2008.

${ }^{11}$ See M. Santagati, 'Researching integration in Multiethnic Italian Schools. A Sociological Review on Educational Inequalities', Italian J ournal of Sociology of Education, 7, 3, 2015, pp. 294-334. These 20 Italian studies are selected among out of 100 sociological studies carried out from 1990 to 2015.

${ }^{12}$ I will refer mainly to the following texts: G. Favaro, I colori dell'infanzia, Milano: Guerini, 1990; E. Fravega, L. Queirolo Palmas (ed.), Classi meticce, Roma: Carocci, 2003; E. Besozzi (ed.), I progetti di educazione interculturale in Lombardia, Milano: ISMU, 2005; G. Maggioni, A. Vincenti, Nella scuola multiculturale, Roma: Donzelli, 2007; A. Torre, F. Lagomarsino, La scuola "plurale" in Liguria, Genova: il melangolo, 2009; R. Serpieri, E. Grimaldi, Che razza di scuola, Milano: FrancoAngeli, 2013. 
Educating the children of migrants, has called for a greater effort of individual States in managing the consequences of immigration on educational systems. This is based on the idea that diversity is to be considered a "normal situation" and schools should strive to ensure migrant students' talent is retained and not dissipated, as this would imply a loss in terms of social, cultural and economic development incurred by the whole of society. It is important to bear in mind that previously multiculturalism was the dominant paradigm for the integration of immigrant pupils in Europe. This approach developed prevalently in the 1970s in countries with a long-standing history of immigration and aimed to foster recognition and respect for minority cultures, promoting equal rights and opportunities for every cultural group ${ }^{13}$. At the end of the last century, however, scholars ${ }^{14}$ and politicians ${ }^{15}$ started to criticize multiculturalism on the grounds that such an approach, by encouraging different cultural groups to live separate and sometimes parallel lives, would create a divisive society. This model also seemed to tolerate segregated communities behaving in ways that run counter to democratic values, generating educational contexts aimed at preserving separate identities. Given the limits of multiculturalism and the contradictory effects which it has generated in the social contexts where it has been implemented, in the EU interculturalism has been preferred to multiculturalism ${ }^{16}$.

Interculturalism, in the EU perspective, is synonymous with intercultural dialogue, understood as a process that comprises an open and respectful exchange of views between individuals and groups with different ethnic, cultural, religious and linguistic backgrounds (White Paper on Intercultural Dialogue, 2008, Council of Europe). It entails the freedom and ability to express oneself, as well as the willingness and capacity to listen to the views of others. Intercultural dialogue is understood as contributing to political, social, cultural and economic integration and the cohesion of culturally diverse societies ${ }^{17}$.

In schools this translates into intercultural education that represents a sort of "framework for integration", characterized by four dimensions ${ }^{18}$ : a focus on interpersonal relationships, through the promotion of tolerance and dialogue at school; a focus on knowledge, through a commitment to intercultural teaching in each discipline and across disciplines; a focus on interaction and exchange, through the development of integrated extra-curricular activities; a focus on integration, through the adoption of target-based schemes for non-Italian pupils. Intercultural education is aimed not only at fostering integration among immigrants, but also at undermining prejudice and promoting openness to difference among members of the majority culture.

\footnotetext{
${ }^{13}$ Banks and Banks also identified a wide variety of educational programs and practices - which form part and parcel of a "multicultural education" - whose major goal is to guarantee an equal educational chance to students who are members of diverse racial, ethnic, linguistic, and cultural groups. J.A. Banks, C.A.M. Banks, Multicultural education: issues and perspectives, J ohn Wiley, 2001.

${ }^{14}$ See for example: R. Bernstein, Dictatorship of virtue: multiculturalism and the battle for America's future, New York:

Vintage Books, 1994; A. Heat, N. Demireva, 'Has multiculturalism failed in Britain?', Ethnic and Racial Studies, vol. 37 (1), 2014, pp. 161-180.

${ }^{15}$ This criticism was also expressed by politicians, such as the British Prime Minister David Cameron, echoing the remarks of German Chancellor Angela Merkel in 2011.

${ }^{16}$ The multicultural paradigm has never taken root in Italy and it is a concept that has always been absent from Italian public policy and discourse. See R. Armillei, 'A multicultural Italy?' in F. Mansouri (ed.), Cultural, Religious and Political Contestations: The Multicultural Challenge. Switzerland: Springer International Publishing, 2015, pp. 135-151.

${ }^{17}$ L. Bekemans (ed.), Intercultural Dialogue and Multi-level Governance in Europe, Peter Lang, 2012.

${ }^{18}$ M. Catarci, M. Fiorucci, Intercultural Education in the European context: theories, experiences, challenges, New York: Routledge, 2016.
} 
Echoing Giménez's definition, interculturalism is founded on a vision of education that respects the cultural diversity of the learner through the provision of culturally appropriate and responsive education for all (right to difference); provides every learner with the cultural knowledge, attitudes and skills necessary to acquire full participation in society (right to educational equality); and enables them to contribute to an increased respect, understanding and solidarity among individuals, ethnic, social, cultural and religious groups and nations (positive interaction among different people). Within this frame, it is interesting to evaluate the EU's adherence to the aforementioned three principles which are considered here at the root of interculturalism.

In terms of equality, empirical results show that immigrant students still haven't achieved equal opportunities in the European educational systems: compared to natives, they show persistent disadvantages in the learning process, and are at higher risk of failure and drop-out. The analysis of two different indicators - Early Childhood Education and Care (ECEC) and Early School Leaving (ESL) - highlights the disparity which penalizes foreign-born students compared to natives in late access to schooling and premature exit from the education system ${ }^{19}$. The recent Eurydice/Eurostat report on ECEC in Europe indicates that all disadvantaged children have a lower participation in preschool educational provision ${ }^{20}$. The percentage of children who have attended ECEC in European countries (93.9 per cent in 2012 ranging from age four to the start of compulsory education) is very high. The results of the OECD PISA 2012 study $^{21}$ offer some additional information: the data confirm that, at the beginning of the 21st century, non-immigrant students were more likely to attend ECEC for more than a year compared to first/ second generation immigrants. On average, in Europe the difference in participation is approximately 12 percentage points less for the children of immigrants. In Italy (-27.9), Great Britain (35.1 in Wales) and Iceland (-28.2) this distance appears particularly high.

A second useful indicator in the comparative analysis is that of Early School Leavers (ESLs). ESLs represent the subset of 18 to 24-year old who do not have a secondary education degree or a professional qualification and that do not attend school or Vocational Education and Training (VET) courses. The most recent data published by Eurostat confirms immigrants' disadvantage when it comes to school drop-out: in 2014 the percentage of ESLs in Europe was 10.2 per cent among natives, but increased twofold (23.2 per cent) among immigrants of European origin, and the number is even higher among non-EU nationals (25.5 per cent). The gap between native and non-native students is particularly high in Greece, Italy and Spain. Indeed, where the percentage of ESLs is greater, so is the difference between natives and immigrants. In these countries, ESLs still represent a large portion of all non-native students in Spain (38.3 per cent), Greece (36.5 per cent), and Italy (34.4 per cent). The UK is the only country in which immigrants have a lower rate of ESLs compared to natives (9.9 per cent versus 12.8 per cent).

\footnotetext{
${ }^{19}$ See M. Santagati, A different yet equal opportunity. Innovative practices and intercultural education in Initial VET, Milan: ISMU, 2016.

${ }^{20}$ European Commission, Key data on Early Childhood Education and Care in Europe. Eurydice and Eurostat Report, Luxembourg: Publications Office of the European Union, 2014.

${ }^{21}$ The Programme for International Students Assessment (PISA) is a triennial international survey promoted by the OECD, which aims to evaluate education systems worldwide by testing the skills and knowledge of 15-year-old students. It has been carried out in six editions (2000, 2003, 2006, 2009, 2012, 2015). In 2015 over half a million students in 72 countries were assessed in science, mathematics, reading, collaborative problem solving and financial literacy.
} 
More generally, according to recent analyses conducted by the Migrant Integration Policy Index (MIPEX 2015) ${ }^{22}$, education emerges as the greatest weakness in integration policies in most countries compared to other areas considered by MIPEX (labour market mobility, political participation, access to nationality, family reunion, health, permanent residence, anti-discrimination). Of the 38 countries considered, 20 are characterized by inadequate educational policies (this group includes many countries of Southern Europe such as Spain, Italy, and Greece and of Eastern Europe such as Bulgaria, Hungary and Croatia). Indeed, according to MIPEX 2015, interventions aimed at improving access to education are still few and far between, especially those geared to preschool services, VET and higher education. In many cases governments trust any potential learning problems among the children of immigrants will find a solution in the general functioning of education systems. In Greece, Italy and Spain, weak education policies have not caught up with the now relatively large numbers of immigrant students.

With regard to the principle of recognition of cultural diversity - always according to MIPEX 2015 data - in most cases (i.e. Austria, Nordics, Switzerland), minority languages and cultures are taught only to immigrants, typically during extracurricular activities. School curricula need to better incorporate diversity: minority children often find it difficult to identify and engage with the learning process and the content of a mono-cultural curriculum. Overall, addressing religious, ethnic and other forms of diversity remains a critical aspect of education ${ }^{23}$.

As for the principle of positive interaction between people belonging to different cultures this seems to be the least consolidated among European nations. However, the MIPEX 2015 report shows that schools in most countries are required (but without receiving any specific funds) to teach all pupils how to live and learn together in a diverse society (this is especially true in Denmark, France and the newer countries of immigration). Most European countries still tend to use traditional teaching methods and the appreciation of cultural diversity is mostly just a topic for voluntary teacher training and a government budget line for ad hoc projects. At present, there is a widespread failure among EU nations to adequately meet the challenge of encouraging ethnic mixing and inter-ethnic cooperation ${ }^{24}$.

Countries like Austria, Belgium, Portugal, United Kingdom, however, are changing and monitoring the curriculum so that pupils can learn about cultural diversity in specific subjects), while others, such as Italy, Sweden, UK, Spain are increasingly looking to interculturalism within citizenship education programs. In the educational courses which have been introduced in these countries, there is an emergent, intercultural concept of citizenship which is gaining ground. In this perspective citizenship encompasses a recognition of differences, the complexity of modern

\footnotetext{
22 Promoted by the British Council and by the Migration Policy Group, MIPEX is a useful reference tool for national educational systems, since it aims at assessing and comparing the commitment to integration of 38 countries (EU Member States, Australia, Canada, Iceland, J apan, South Korea, New Zealand, Norway,

Switzerland, Turkey, and the USA: www.mipex.eu). The study elaborates 167 policy indicators to create a multidimensional picture of migrants' opportunities to participate in society: it has been carried out in four editions (2004, 2007, 2011,2015) and involves a network of national partners and organizations, experts, and country profile contributors.

${ }^{23}$ B. Van Driel, M. Darmody, J. Kerzil, 'Education policies and practices to foster tolerance, respect for diversity and civic responsibility in children and young people in the EU', Luxembourg: Publications Office of the European Union, 2016.

${ }^{24}$ Ibid.
} 
societies, and promotes inter-ethnic and intercultural relationships, the prevention of conflict and the defence of human rights ${ }^{25}$.

\section{The 'I talian way' of managing cultural diversity in education}

In order to highlight its specific strengths and weaknesses, the analysis of the Italian case must be undertaken bearing in mind the complex European scenario. In the past 20 years, the presence of pupils of immigrant origin has become a structural and stable phenomenon in Italy and a specific target of education policies. The last report published by the Ministry of Education and the ISMU Foundation offers a clear picture of pupils with non-Italian citizenship in the 2014/ 15 academic year ${ }^{26}$ : a total of 814,187 students (9.2 per cent of the total school population); a significant rise in children born in Italy (55.3 per cent of all non-Italian students); an extreme diversity in national origin, with Romanians, Albanians, Moroccans and Chinese as the largest minority groups; consistent rates of school failure or delay, greater risk of school drop-out, poorer outcomes in learning compared to their Italian counterparts; and a greater likelihood of pursuing VET routes instead of mainstream schooling ${ }^{27}$. Foreign students tend to be over-represented in professional careers, such as technical or professional colleges or vocational training centers, with a greater likelihood of attending shorter educational courses, and a higher risk of obtaining lower qualifications and early school leaving.

These last descriptive elements already indicate that the intercultural model is facing various difficulties in ensuring equal opportunities for immigrant students ${ }^{28}$. Albeit with advanced legislation, the application of interculturalism in Italy is still uncoordinated and scarcely consistent: there are divergences between legislation, official documents, school choices, and the opinions of teaching staff. Moreover, there is a weak correlation between policy and organizational and institutional practices, to which I will now turn.

\section{Interculturalism as guarantee of educational equality}

Since the first inflow of immigration in 1989, Italian schools have ensured open access to all immigrant minors, regardless of their legal status, in order to grant their right to take part in compulsory education. The abolition of "special classes" was implemented in 1977 with Law 517 for students with disability, a choice which put forth a new educational model based on flexible modules or group activities conducted by specialized teachers. Consequently, Italy chose an integrated model also for immigrant pupils, ${ }^{29}$ that favors the allocation of non-Italian students in classes of children of the same age-group in mainstream education. It is based on the idea that immigrant students will benefit - both academically and socially - if

\footnotetext{
${ }^{25}$ M. Santerini, Educare alla cittadinanza. La pedagogia ele sfide della globalizzazione, Roma: Carocci, 2001. ${ }^{26}$ MIUR, ISMU (ed. by M. Santagati, V. Ongini), Alunni con cittadinanza non italiana. La scuola multiculturale nei contesti locali. Rapporto nazionale A.s. 2014/ 15, Milano: ISMU, 2016.

${ }^{27}$ See Santagati, op. cit., 2016.

28 See M. Ambrosini, 'Immigration in Italy: Between Economic Acceptance and Political Rejection', J ournal of international migration and integration, 14, 2013, pp. 175-94.

29 This model has been identified in the Eurydice network survey, Integrating Immigrant Children into Schools in Europe, Brussels: European Commission, 2004. Italy, Ireland, and United Kingdom (Scotland) chose in Europe the integrated model for immigrant students. Within the mainstream education, these countries offer the same methods and curricular content designed for native pupils. Support measures (essentially linguistic) are implemented for each pupil during normal school hours or via extracurricular tuition.
} 
they are integrated with other pupils and not allocated to separate ad hoc classrooms.

Education has emerged as the most inclusive area in Italy, compared to other contexts where there has been more discrimination for culturally different minorities. For example, Italy is one of the most restrictive countries when it comes to granting citizenship status, which is based prevalently on the jus sanguinis principle, although this aspect is currently the object of reform. ${ }^{30}$ Students with non-Italian citizenship as they are defined by the official statistics - they include almost the entire group of young immigrants, whether they were born in Italy or abroad. They have been granted access to the school system, but, for the most part, without having acquired the juridical status of citizens. Moreover, universal access to education does not always translate into equal opportunities, especially in those schools with a high percentage of immigrant students, with insufficient economic resources and a lack of specific training among teachers. Indeed, schools have developed different practices in the evaluation of pupils' competences upon entry and their allocation to a given class, ${ }^{31}$ failing to ensure uniformity in reception procedures. A study of interculturalism conducted in the province of Cuneo in North Western Italy, for instance, recorded different practices for the reception of migrant students which have been adopted in a non-uniform manner across the various schools. These include: specific modes of enrolment for migrant students and families, plurilingual enrolment forms and other communication material, specific entry tests aimed at evaluating linguistic and other educational competences, personalized educational plans, guidance counselling.

A study on immigrant students attending secondary schools in Lombardy ${ }^{32}$ has highlighted that recent immigrants (especially adolescents or preadolescents) were often allocated to classes with younger peers and this has generated a delay in school entry which represents the greatest disparity between natives and first generation immigrants. This initial choice operated by schools - i.e. to manage the emergency of recent immigrant arrivals with a retrocession in the education system $^{33}$ - has had many implications on pupils' subsequent educational career (such as the choice of shorter educational paths and early school leaving), despite a strong motivation to succeed. Moreover, another study on non-Italian adolescents in VET system in the province of Turin ${ }^{34}$ highlights that educational failure among migrant students is also linked to school effectiveness, which is affected by the following critical aspects: a poor knowledge of foreign educational systems and languages among many Italian

\footnotetext{
${ }^{30}$ The reform of citizenship is currently being discussed in the Senate House. According to the new law proposal, children born in Italy from at least one parent with a regular, longstanding residency stay will automatically become Italian citizens at birth. Alternatively, for those children who have arrived in Italy before age 18, citizenship can be obtained only after the completion of an educational or training cycle.

31See M. Santagati (ed.), Il mondo a scuola, Cuneo: Fondazione CRC, 2013.

32 M. Colombo, M. Santagati, 'Interpreting social inclusion for young immigrants in Italy', Italian J ournal of Sociology of Education, 1, 2010, pp. 4-48. Most of Italian studies are conducted in local contexts, although there are also few relevant nationwide experiences. Worth noting that Lombardy, that is the region that hosts the majority of pupils without Italian citizenship (nearly $25 \%$ of the foreign students in Italy), is the region with most empirical research in this sector. Only a small number of studies have been conducted in the Centre and in the South of Italy, where the size of non-Italian students in the educational system is notably smaller.

33 The report published by MIUR and ISMU (op. cit., 2016, ed. by Santagati and Ongini) analyzes the characteristics of new migrant pupils. Between 2007/ 08 and 2014/ 15, they dropped from 40,154 to 33,054. There was a new surge in the last year ( $+10,218$ from 2012/ 13 to 2014/15), however, which can be partly explained by the significant rise in family reunions and an increase in the arrival of unaccompanied minors (10,536 in 2014). Unfortunately, in Italy we still lack data on school entry for unaccompanied minors, asylum seekers and refugees. 34 M. Santagati, Formazione chance di integrazione, Milano: FrancoAngeli, 2011.
} 
teachers, a focus only on Italian as a curricular language, a widespread difficulty among teaching staff in relating with immigrant families, and a tendency to underestimate (or non-evaluation of) immigrant pupils' non-linguistic skills and competences.

Given the tendency of schools and teachers to focus their attention primarily on Italian learning on the one hand and on newcomers on the other, support activities connected with Italian as a second language (L2) teaching have been successfully implemented and various school projects have been put in place, with a significant mobilization of economic and human resources. Together with ordinary funding, specific resources have been allocated annually by the Ministry of Education since 2001 for schools in "areas under migratory pressure". However, such resources have progressively decreased undermining the projects' continuity. These projects have focussed on Italian L2 workshops and on the introduction of "linguistic facilitators", both teachers trained in Italian L2 teaching and external consultants. Many projects have also led to the development of new teaching materials for non-Italian students, which have contributed to defining a new model of basic Italian communication competences' (ItalBase) and the identification of problems with 'Italian for academic purposes' (ItalStudio), in order to offer a common framework for all teachers ${ }^{35}$.

As Colombo suggests ${ }^{36}$, however, among Italian L2 teachers there is a paucity of experience, much improvisation and more voluntarism than professionalism. It is thus essential to increase the use of instruments for the evaluation of Italian language competences based on the "Common European Framework of Reference for Languages" (CEFR) in order to develop targeted interventions. ${ }^{37}$ The CEFR provides a common basis for the development of language syllabuses, curriculum guidelines, examinations, and textbooks across Europe. It describes in a comprehensive way what language learners have to learn to do in order to use a language for communication and what knowledge and skills they have to develop so as to be able to act effectively. The Framework also defines levels of proficiency which allow learners' progress to be measured at each stage of learning and on a life-long basis. Italian L2 certification (which attests linguistic knowledge and skills according to EU standards) has yet to gain popularity in Italian schools, but may be useful both for students (in the transition from one school to another, when returning to education and in the transition to the workplace) and for the development of specific, certified teacher training. The latter, in particular, is aimed at introducing tools for the definition of different levels of Italian language competence according to common European standards and for planning specific interventions geared at responding to the needs of learners.

Finally, two other issues related to the problem of equal opportunities for immigrant students are in relation to secondary school choices and academic success. Research has shown that in Italy immigrant students are often 'channelled' towards VET (as opposed to regular schooling) and have a greater likelihood of accumulating school delays and negative performances, over and beyond their native peers, independently of socio-economic status ${ }^{38}$. This indicates that there is a need to invest more in

\footnotetext{
35 See Ministero della Pubblica Istruzione, La via italiana per la scuola interculturale el'integrazione degli alunni stranieri, Roma, 2007.

${ }^{36}$ M. Colombo, 'Working in mixed classrooms: Teachers' reactions and new challenges for pluralism', Italian Journal of Sociology of Education, 5, 2, 2013, pp. 17-45.

${ }^{37}$ Cf. http:// www.coe.int/t/dg4/linguistic/Source/ Framework_EN.pdf.

38 Colombo, Santagati, op. cit., 2010.
} 
supporting secondary school choices among immigrant families and students, by developing widespread, structural and longstanding actions, which can enhance disadvantaged pupils' access to and participation in a high quality education. These measures remain urgent, especially in lower secondary education and for those who are facing linguistic difficulties as a result of their recent migratory experience. After a longstanding effort to ensure immigrant minors are granted the right to enjoy access to education of good quality, it is now necessary to turn our attention to academic results as well. This can be done by developing policies to prevent drop-out, in partnership with VET agencies who represent an opportunity for educational integration for those immigrants with more troubled and erratic life stories ${ }^{39}$.

\section{I nterculturalism as promotion of cultural diversities}

The Italian school system recognizes the importance of protecting minority languages, but has not developed any structural measures to ensure this, such as the presence of teachers with knowledge of immigrant pupils' native languages or the development of bilingual school programs. ${ }^{40}$ Some projects carried out in Italy $^{41}$ include, for example, the creation of networks between schools and territorial organizations, interdisciplinary interventions, an integrated approach to resources and knowledge, and training for first language (L1) and second language (L2) teachers. The promotion of plurilingualism and the maintenance of students' mother tongue, as precious resources for the educational experience, ${ }^{42}$ is an issue which is still at the margins of the educational discourse. Educational practices - still prevalently monocultural - have yet to catch up with the most recent findings of research on bilingualism/ plurilingualism and with the Italian and European legislative guidelines. Linguistic diversity no doubt represents a challenge for Europe, as the European Commission stated in 2008, but only "imaginative management of linguistic diversity can indeed boost European integration, promote citizenship and the feeling of belonging to the European Union. It could even give European integration fresh impetus and a new lease of life" ${ }^{43}$ A similar position has been put forth also by the Italian Ministry of Education in 2007, by suggesting that supporting migrants in maintaining their native language can become a tool for cognitive development, with positive effects also on Italian language learning. Once again, however, despite official recommendations, pedagogical practices lag behind.

\footnotetext{
39 Santagati, op. cit., 2011.

40 An example of such programs is the Rucksack project, conducted in Holland at the end of the 1990s and then exported to Austria, Spain and Germany. The project, aimed at immigrant children and their families and primary school educators, aims to develop second language learning at school and, simultaneously, trains teachers and parents to support mother tongue learning at home. An evaluation of these projects suggests a great strength is the improvement of children's linguistic competences both in L1 and in L2, as well as a greater involvement of families in their children's educational life. A weakness of the project is connected to the fact that it targets only migrant parents but does facilitate intercultural openness and an attention to plurilinguism among native families. Cf. S. Cantù, A. Cuciniello, Plurilinguismo. Sfida e risorsa educativa, Milano: ISMU, 2012.

${ }^{41}$ Ibid. See for example, the "Apriti Sesamo" project (2005-2008), carried out by the ISMU Foundation, as a bilingual programme (Arabic and Italian) for students and teachers.

42 The research suggests that strengthening native languages can have a positive impact on the academic results of immigrant students, producing a re-evaluation of the family's cultural capital and increasing self-esteem, as well as being an occupational advantage both in Italy and in their home country See NESSE network, Education and Migration. Strategies for integrating migrant children in European schools and societies, Brussels: Education \& Culture DG, 2008.

${ }^{43}$ European Commission, A rewarding challenge. How language diversity could strengthen Europe, Brussels: Education \& Culture DG, 2008, p. 14.
} 
In terms of diversity management, since 1990 the Italian Ministry of Education has given schools the possibility of using "cultural mediators" in order to facilitate communication and school-family relations and promoting minority languages and cultures. ${ }^{44}$ The role of cultural mediators has been regulated for the first time in 1998, with Law n. 40, which allows a great degree of freedom both regarding who can become a mediator (in terms of qualifications and training) and regarding their employment by educational institutions (in terms of types of contract). The occasional presence of cultural mediators, however, cannot be considered an adequate strategy to maintain students' culture of origin ${ }^{45}$.

\section{Interculturalism as positive interaction between students of different origins}

Finally, in terms of the positive interaction between people belonging to different cultures (the final element of the Giménez's definition of interculturalism), the Italian Ministry of Education (Document 205/1990) has defined the role of intercultural education as the fostering of "positive coexistence, preventing the creation of stereotypes and prejudices towards other peoples and cultures and overcoming any form of ethnocentrism". A few years later the Ministerial Document 73/ 1994, entitled Intercultural Dialogue and Democratic Coexistence: The Planning Commitment of the Schools, represented the first systematic effort to shape what would later become "The Italian approach to Interculturalism". Intercultural education is defined

not merely as a response to the issues raised by the presence of pupils of immigrant origin, but includes the complex issues deriving from the contact between different cultures [...] as one of the most important strategies to combat racism. [Interculturalism] includes the possibility of reciprocal discoveries, while respecting individual and collective identities, in a climate of dialogue and solidarity (C.M. 73/ 1994).

The document stresses the fact that positive social values are not to be found all in one culture, be it Italian culture or other cultures. It is thus necessary to appreciate different cultures in terms of both their strengths and weaknesses and to recognize the universal value of individual persons as the foundation of a common culture. A relativist approach thus morphs into a universalist vision: the recognition of difference is possible if the common framework is based on shared similarities. Likewise, intercultural education is based on unity and diversity and their dialectic and constructive dialogue in a multicultural society.

With the MIUR document of 2007, The Italian way for intercultural education and the integration of immigrant pupils, the Italian model of educational integration is further detailed. While reaffirming immigrants' right to education, the document stresses that interculturalism is connected with the pedagogical management of changes which are taking place in schools, with the challenge of social cohesion, and with the conditions of intercultural exchange. This has translated into interventions

\footnotetext{
${ }^{44}$ The role of the cultural mediator is to support an immigrant subject in his or her relationships with the institutions of the host society (i.e. schools and hospitals), offering information and guidance to those who have recently arrived. As a member of the immigrant's culture of origin, moreover, he or she can intervene to translate and facilitate communication and understanding and to prevent and manage any conflicts which may arise. See M. Santagati, Mediazione e integrazione, Milano: Franco Angeli, 2004.

45 As shown by a research carried out in Liguria. Cf. Torre, Lagomarsino, op. cit.
} 
aimed at improving relationships at school (both with teachers and with peers) to be carried out during curricular and extra-curricular activities, aimed at combating discrimination and prejudice, and integrating intercultural perspectives in knowledge and competences. Interventions include: disciplinary or multidisciplinary intercultural teaching, revision of the curricula, extracurricular activities. These strategies are aimed at transforming the classroom in an arena for intercultural communication and cooperation, fostering the participation of all pupils in the process of knowledge construction. Clementi wrote of experiences conducted across Italian regions and territories where schools have completely revised the syllabus for certain disciplines, on the basis of an intercultural approach, ${ }^{46}$ recognizing the contribution of different cultures and overcoming ethnocentric/ Eurocentric approaches in teaching history or languages.

Despite some positive experiences, however, in many schools there is still a lack of awareness of the aims, the actions and the approaches to adopt in order to foster a true intercultural perspective. This is what emerges, for example, from the survey conducted by the "Database of Intercultural Education Projects" (BDEI) in Lombardy. This database (managed by the ISMU Foundation and Lombardy Regional Government) includes 2,000 projects and is the only example of an effort to monitor and analyze school projects on interculturalism in Italy. ${ }^{47}$ The database is an interesting experience also because it offers a model for the evaluation of different projects (mostly in terms of new project development rather than an evaluation of efficiency or efficacy), albeit without a thorough analysis of actions and results.

The BDEI statistics suggest that the most significant experiences conducted within single schools are still too isolated and remote, and their success is often connected to the actions carried out by small, innovative groups who are unable to disseminate and spread their results and, more importantly, to ensure they reach broader stakeholders. In practice, those teachers that carry out intercultural projects still confuse different visions of intercultural education, often mixing and matching the role of knowledge and appreciation of other cultures with intercultural dialogue or with a methodological approach that promotes attitudes of openness to otherness. The everyday practices in intercultural practices highlight the conceptual uncertainty that cannot be resolved by the prefix "inter", which should serve to indicate the core role of interactions between groups, individuals and cultures. ${ }^{48}$

There is still much work that needs to be done for the development of a climate of intercultural exchange, especially in those schools with a high percentage of immigrant pupils, which are often situated in difficult and disadvantaged areas. ${ }^{49}$ Highly conflictual climates, marked by negative sentiments towards diversity and violent behaviours, have been identified in a recent study conducted by Colombo and Santagati in lower secondary schools with a large number of students of immigrant

\footnotetext{
46 See M. Clementi, La scuola eil dialogo interculturale, Milano: Ismu, 2008.

${ }^{47}$ The BDEI projects are considered of good quality, according to the criteria established by the author and other ORIM (Regional Observatory on Integration and Multiethnicity; based in Lombardy) researchers, if: a) aims, instruments, resources and evaluation of results are made clear; b) they are inclusive of the school on the whole; c) they have a network of partners; d) there is an acquisition of methodological and didactic competences; e) there is an impact on methods, contents and educational roles. Cf.

http:// www.orimregionelombardia.it/ area.php?ID=9.

48 Favaro, op. cit.

49 As suggested by various studies on intercultural practices in Italian schools across different regions: Besozzi, op. cit., 2005 (Lombardy); Fravega, Queirolo Palmas, op. cit. (Liguria); Maggioni, Vincenti, op. cit. (Emilia Romagna, Marche); Serpieri, Grimaldi, op. cit. (Campania).
} 
origin, at risk of ethnic segregation. ${ }^{50}$ The study is carried out using qualitative methods (interviews and focus groups with teachers of secondary schools) and a survey conducted on a sample of 1,040 Italian and non-Italian lower secondary school students in Lombardy. Specific measures of highly conflictual climates have been generated by observing in the offensive language used during instances of peer conflict, the development of negative attitudes towards diversity, and the presence of aggressive and violent behaviour. In these challenging situations cooperative learning strategies seem to foster processes of acceptance and the integration of pupils of immigrant origin in the classroom ${ }^{51}$. Research has shown that cooperative learning is a methodology that fosters positive interethnic interactions in groups made up of learners of different ethnic (or other) origin, because it works on the interdependency of aims, which cannot be achieved without the contribution of each member of the group: everyone is responsible for an aspect of the project and groups are evaluated on the basis of the performances of each member. ${ }^{52}$ In multi-ethnic schools those teachers who want to improve the classroom's relational climate necessarily have to change the organization of their classes in order to make them compatible with a cooperative approach, and reap the benefits both in terms of relational satisfaction and academic performance. This is something that the study on schools with a high percentage of immigrant pupils confirmed: ${ }^{53}$ academic success can never be separated from the development of positive relationships. The research, in fact, developed an index of school integration that can measure the level of integration in multi-ethnic classrooms by looking at the following factors: peer relationships in the classroom, the relationship between students and teachers, peer conflict (participation in fights, racist episodes, prevarications), academic achievement (average grades), level of "academic" Italian ${ }^{54}$.

The same study also identified the best school experiences, which might be transferred and reproduced elsewhere. Positive class climates, for example, seemed characterized by the following elements: the development of interethnic friendships, interracial couples, and mixed study and friendship groups ${ }^{55}$. The conditions which promote positive relations between peers with different cultural background are generated mainly as a result of school actions which foster the development of a sense of belonging to the peer group, as well as to the educational institution more broadly. The analysis carried out by Colombo and Santagati (2014) points out that extracurricular activities (study groups, recreational activities, artistic or musical programs) promoting aggregation on the basis of common interests and spontaneous

\footnotetext{
50 Colombo, Santagati, op. cit. (in press). See also M. Colombo, M. Santagati, Nelle scuole plurali, Milano: Franco Angeli, 2014.

51 See also the Didattica del fare, fare per includere study carried out by the ISMU Foundation, which monitored 20 school projects across Italy during the school year 2014/ 15. The projects were chosen on the basis of the following criteria: innovation and inclusivity, appreciation of differences, ability to include all students and implement the intercultural approach within the school system. Cf. http:/ / www.ismu.org/ didattica-del-fare-fareper-includere/.

${ }^{52}$ J. H. Pfeifer, C. S. Brown, J. Juvonen, 'Prejudice Reduction in Schools. Teaching Tolerance in Schools: Lessons Learned Since Brown v. Board of Education About the Development and Reduction of Children’s Prejudice', Social Policy Report, XXI(II), 2007, pp. 3-23.

53 Colombo, Santagati, op. cit., 2014.

54The index presents a positive association with the following variables: gender (females are more integrated than males); citizenship (Italian students are the most integrated, followed by second generation and first generation students); high socio-economic status and cultural capital; high parental satisfaction with their children's school experience; an intrinsic and expressive motivation to learn; wellbeing at school; the adoption, on teachers' part, of measures to foster the integration of immigrant students. What is particularly relevant is that the level of integration, from the point of view of positive academic results and good interethnic relations, does not seem to diminish with an increase of immigrant students in the classroom. See Colombo, Santagati, op. cit. (in press). 55Ibid.
} 
interactions provide a general boost to the classroom's relational climate. A positive climate is also supported by taking advantage of the presence of particularly charismatic young immigrants and supporting their identification as 'peer leaders': this strategy can significantly improve students' level of integration by contributing to the development of a positive representation of students belonging to a stigmatized or disadvantaged minority, which gradually comes to take on the positive characteristics of these individuals ${ }^{56}$.

Finally, the development of school well-being, always according to the research findings outlined by Colombo and Santagati, is strongly correlated to the quality of 'teacher-pupil' relations. The challenge for teachers is to develop a reflexive approach to the contents of their knowledge, to their communication style with pupils, to their relationships with colleagues, and to their mode of addressing parents, in order to adopt an egalitarian approach to all students. Teachers need to become experts in managing multicultural groups, developing the ability to deal with ethnically-based conflicts and the awareness of having most of the responsibility for the development of a positive classroom climate. Integration is generated as a result of teachers' agency and of the support they offer to pupils with an immigrant background, which is able to compensate the negative impact of schools' ethnic composition ${ }^{57}$.

\section{Conclusion}

Italy's early interest in interculturalism of the 1990s currently seems to be in decline. A rapid rise in pupils without Italian citizenship has been recorded at a time when resources and social security measures are increasingly restricted ${ }^{58}$. To sum up, the Italian education system has not always been able to ensure equal opportunities and the right to education for students with an immigrant background. Indeed, as I have tried to argue throughout this paper, educational inequalities still remain. What has also not changed is the Italian educational system's difficulty in managing the arrival of these pupils and considering them as an opportunity for all students (see for instance the absence of other languages and cultures from school curricula) ${ }^{59}$. The intercultural option, as it has been defined in official documents, has turned out to be ambiguous when translated into practice. Besides, not only intercultural education has not been implemented homogeneously within the Italian school system, but for the most part still needs to be monitored and evaluated.

Italy's other complex challenge today is linked to the lack of conformity between education and immigration policies. The intercultural approach adopted by Italian schools, albeit with its difficulties of application, is not reflected in the broader model of social integration. Italy is characterized by what can be defined as an implicit

\footnotetext{
56 Ibid.

${ }^{57}$ As also confirmed by O. Agirdag, M. Van Houtte, P. Van Avermaet, 'Ethnic School Segregation and Self-Esteem: The Role of Teacher-Pupil Relationships', Urban Education, 47, 6, 2012, pp. 1135-59.

58The Dambruoso-Maciulli Law, "Measures for the prevention of radicalization and J ihadist extremism", proposed in J anuary 2016 and currently under parliamentary discussion, is precisely an example of the change of the current political climate in Italy. The law calls for the creation of opportunities for intercultural and interreligious dialogue in order to prevent violent radicalization and combating religious-based terrorism, starting from the school environment.

${ }^{59}$ As argued by MIPEX researchers. See J . Niessen, T. Huddleston, Migration Integration Policy Index IIII Italia, Bruxelles: British Council, Migration Policy Group, 2011. In this regard education policies seem to be more advanced in those countries with a consolidated tradition of immigration, where interventions were developed according to the multicultural mainstream (Australia, Canada, New Zealand), but also with measures aimed at targeting individual needs (Northern Europe) or positive discrimination actions towards more vulnerable ethnic or racial minorities (USA).
} 
model of 'subordinate integration', 60 which reveals a clear contradiction between security fears and humanitarian demands. In other words, immigration management is geared more at responding to emergency situations rather than planning long-term interventions. Although migration became a hot political topic over the years, the available resources are still limited, representing a clear obstacle to the development and implementation of comprehensive inclusion policies ${ }^{61}$. These contradictory elements make it difficult to define the Italian version of interculturalism as a good or bad model of integration. More studies are thus necessary to monitor and evaluate the strengths and weaknesses of immigration and education policies, developing further indications and guidelines on how to better put intercultural values into practice. 